\title{
Respiratory syncytial virus genotypes and disease severity among children in hospital
}

\author{
Jonathon N Fletcher, Rosalind L Smyth, Huw M Thomas, D Ashby, C Anthony Hart
}

University of

Liverpool: Department of Medical

Microbiology and

Genito-Urinary

Medicine

J N Fletcher

R L Smyth

H M Thomas

C A Hart

Department of Child

Health

R L Smyth

D Ashby

\author{
Department of \\ Paediatrics, \\ Southmead Hospital, \\ Bristol \\ H M Thomas \\ Correspondence to: \\ Professor C A Hart, \\ Department of Medical \\ Microbiology and \\ Genito-Urinary Medicine, \\ University of \\ Liverpool, Liverpool \\ L69 3BX. \\ Accepted 10 July 1997
}

\begin{abstract}
Objectives-To determine the spectrum of $\mathbf{N}$ and $\mathbf{G}$ genotypes of respiratory syncytial virus (RSV) causing respiratory tract infection and whether particular genotypes are associated with severity of infection.

Patients and methods-Nasopharyngeal aspirates (NPAs) were obtained from 114 infants with acute respiratory tract infection due to RSV over two seasons. Viral mRNA was extracted from NPAs or cultured virus, reverse transcribed, and the cDNA amplified by the polymerase chain reaction using primers directed to parts of the $\mathbf{N}$ and $\mathbf{G}$ gene respectively. Amplicons were separately digested with four different restriction endonucleases for each gene. The fragments were separated by agarose gel, electrophoresis, and the electrophoretic patterns used to assign the various genotypes. Disease severity was assessed as very mild (upper respiratory tract signs only), mild (coryza and signs of lower respiratory tract infection), moderate (requiring nasogastric or intravenous fluids), and severe (requiring oxygen or ventilation).

Results-Five of the six known $\mathrm{N}$ genotypes were detected, but NP4 and NP2 were found most frequently. There was no association between $N$ genotype and disease severity. Six G (SHL) genotypes were detected. Significantly $(p=0.04)$ more of the infants infected with the SHL2 genotype had severe or moderate disease.

Conclusions-During the seasonal peaks of $\mathrm{RSV}$ respiratory tract infection at least 10 different RSV genotypes cocirculated. While there is no association between $\mathbf{N}$ genotypes and disease severity, infection with the SHL2 G genotype appears to result in moderate to severe disease.

(Arch Dis Child 1997;77:508-511)
\end{abstract}

Keywords: bronchiolitis; respiratory syncytial virus; genotypes

Respiratory syncytial virus (RSV) is the major cause of acute respiratory tract infection throughout the world. ${ }^{12}$ Infection is manifest across a spectrum from mild upper respiratory tract disease to bronchiolitis and pneumonia. Studies of urban populations have estimated that 25 in every 1000 infants will develop RSV bronchiolitis severe enough to warrant hospital admission, ${ }^{3}$ and that about $3 \%$ of these develop respiratory failure and require ventilation. Although there is evidence that factors such as pre-existing cardiopulmonary disease, ${ }^{4}$ prematurity, ${ }^{5}$ parental smoking, ${ }^{6}$ and atopy ${ }^{7}$ may predispose to severe bronchiolitis and death from RSV infection, the mechanisms by which this occurs are not understood.

Although RSV poses such a large threat, our understanding of its pathogenesis and prevention is limited. For example, severe infection can occur despite the presence of large amounts of maternally acquired antibody (the peak age for RSV bronchiolitis is 1-2 months). In contrast, when high titre RSV antiserum has been given it has resulted in prevention or amelioration of infection in infants who are at high risk of severe RSV disease. ${ }^{8}$ Unfortunately, a formalin inactivated whole RSV vaccine did not protect vaccinees, but augmented the severity of RSV lower respiratory tract disease during subsequent natural infection. ${ }^{9}$ As a result of this, current work is focused on developing subunit vaccines. ${ }^{10} \mathrm{RSV}$ is a pneumovirus of the genus myxovirus. It has an enveloped negative sense linear RNA genome which encodes 10 genes, including two major surface glycoproteins ( $G$ and $F)$, two matrix proteins $\left(M_{1}\right.$ and $\mathrm{M}_{2}$ ), a small hydrophobic protein ( $\mathrm{SH}$ ), and three nucleocapsid associated proteins $(\mathrm{N}, \mathrm{P}$, and L). ${ }^{11}$ The G glycoprotein mediates attachment of RSV to the cell it is to infect and the F (or fusion) glycoprotein mediates subsequent viral entry into the cell by membrane fusion. RSV is divided serologically into two major groups, A and B, but these can be further subdivided into genotypes based on nucleotide sequence variability. ${ }^{12-14}$ The $\mathrm{N}$ (nucleoprotein) $\mathrm{SH}$ and $\mathrm{G}$ genes have all been shown to have variable sequences. The $\mathrm{N}$ gene is relatively well conserved between virus isolates, but the $G$ gene shows much greater variability. For example, between prototype group A and B RSV G glycoproteins there is only $53 \%$ homology at the amino acid concentration. ${ }^{15}$ The variation in these genes has been used to define RSV typing schemes: $\mathrm{N}$ gene differences resulting in the NP1-NP6 genotypes, while limited restriction mapping and sequencing of the $\mathrm{SH}$ gene has allowed the designation of a series of related lineage groups termed SHL1-SHL6. ${ }^{12}$ Variability in the $\mathrm{G}$ gene sequence has been shown to be closely linked to these $\mathrm{SH}$ lineages. ${ }^{13}$ Previously, analysis of an epidemic of RSV in Birmingham in 1989 revealed that at least six different genetic lineages were circulating at the same time. ${ }^{12} 13$ The purpose of the present study was to determine whether there is any relation between RSV genotype and disease severity. 
Table 1 Distribution of $N$ genotypes according to severity of disease

\begin{tabular}{llclclc}
\hline Severity & \multirow{2}{*}{ NP1 } & \multirow{2}{*}{ NP2 } & NP3 & NP4 & NP5 & Total \\
\hline Very mild & 1 & 1 & 0 & 5 & 0 & 7 \\
Mild & 0 & 12 & 3 & 22 & 1 & 38 \\
Moderate & 0 & 10 & 1 & 17 & 0 & 28 \\
Severe & 1 & 13 & 4 & 22 & 1 & 41 \\
Total & 2 & 36 & 8 & 66 & 2 & 114
\end{tabular}

\section{Subjects and methods}

The 114 infants with RSV included in this study were admitted to the Royal Liverpool Children's Hospital, Alder Hey. They had all been admitted over the period January 1991 to March 1992 (a period covering two separate RSV epidemics) with acute respiratory tract infection. ${ }^{16}$ These patients represent approximately half of those admitted to the hospital with proved RSV infection, and they were selected as part of a larger study of the immunopathology of bronchiolitis. ${ }^{16}$ Nasopharyngeal aspirates (NPAs) and a detailed clinical history were obtained from each patient on admission. Initial diagnosis was by immunofluorescence on part of the NPA sample. The remainder of the NPA was stored at $-20^{\circ} \mathrm{C}$ until analysed further.

Based on clinical features, progression of disease and therapeutic interventions, disease severity was assessed retrospectively as (1) very mild (upper respiratory tract signs only), (2) mild (coryza and lower respiratory tract signs), (3) moderate (as (2) but also requiring nasogastric or intravenous fluids), and (4) severe (as (3) but requiring supplementary oxygen or ventilation). The severity score was taken when the infant was most seriously affected. ${ }^{16}$

RSV mRNA was extracted either directly from NPA samples or from NPA infected tissue culture cells (MA104 cell line) by phenol chloroform extraction as described previously. ${ }^{17}$ RSV cDNA was synthesised by reverse transcription in reaction mixtures $(50 \mu \mathrm{l})$ containing $1 \mathrm{mM}$ of each dNTP, $0.1 \mathrm{mM}$ dithiothreitol, one unit of reverse transcriptase (Life Technologies UK) and $0.15 \mu \mathrm{g}$ poly $\mathrm{T}$ primer. ${ }^{15}$ Reactions were carried out at $41^{\circ} \mathrm{C}$ for one hour. Polymerase chain reaction (PCR) amplification of parts of either the $\mathrm{N}$ gene (between nucleotides 858 and 1135) or the $G$ gene (between nucleotides one and 584) using specific primers, ${ }^{12}{ }^{13}$ was performed on $5 \mu \mathrm{l}$ aliquots of cDNA in reaction mixtures $(30 \mu \mathrm{l})$ containing $250 \mathrm{mM}$ of each dNTP, $1 \mathrm{mM}$ magnesium chloride, $0.4 \mu \mathrm{g}$ of each primer and one unit taq DNA polymerase. PCR programmes for $\mathrm{N}$ gene amplification were $94^{\circ} \mathrm{C}$ for five minutes and then 40 cycles of $94^{\circ} \mathrm{C}$ for 35 seconds, $55^{\circ} \mathrm{C}$ for 35 seconds, $74^{\circ} \mathrm{C}$ for 35 seconds, and finally $74^{\circ} \mathrm{C}$ for two minutes. For

Table 2 Distribution of $G$ genotypes of group A RSV according to severity of disease

\begin{tabular}{lcclclcc}
\hline Severity & SHL1, 3, 4 & SHL2 & SHL5 & SHL6 & $\begin{array}{l}\text { NP2 not } \\
\text { G typable }\end{array}$ & $\begin{array}{l}\text { NP4 not } \\
\text { G typable }\end{array}$ & Total \\
\hline Very mild & 1 & 1 & 0 & 3 & 0 & 1 & 6 \\
Mild & 10 & 13 & 1 & 4 & 2 & 5 & 35 \\
Moderate & 9 & 9 & 0 & 3 & 1 & 5 & 27 \\
Severe & 10 & 17 & 1 & 0 & 3 & 5 & 36 \\
Total & 30 & 40 & 2 & 10 & 6 & 16 & 104 \\
\hline
\end{tabular}

the $G$ gene amplifications, the annealing temperature was increased to $56^{\circ} \mathrm{C}$. The amplicons were separately digested with the restriction endonucleases HindIII, PstI, BgII, HaeII, and RsrI for $\mathrm{N}$ gene typing and $A l u \mathrm{I}$, $M b o \mathrm{I}, \mathrm{MseI}$, and TaqI for G gene typing. Digestion products were separated by electrophoresis on $2 \%(\mathrm{w} / \mathrm{v})$ agarose gels. $\mathrm{N}$ and $\mathrm{G}$ gene lineages were defined from the restriction patterns described previously. ${ }^{12-14}$

\section{Results}

All 114 infants were confirmed as being infected with RSV by direct amplification of the $\mathrm{N}$ gene from NPAs or from NPA infected tissue culture cells. The amplicon from each sample was subjected to restriction endonuclease digestion with the appropriate enzymes followed up with agarose gel electrophoresis. Overall, the majority were in N genotypes NP2 and NP4, these being detected in 36 and 66 patients respectively (table 1). In the first epidemic, which lasted from January to July 1991, the NP2 and NP4 genotypes were evenly distributed ( 31 and 34 patients respectively). In the second epidemic, however, (September 1991 to March 1992) the majority were NP4 (32 cases) with the minority being NP2 and NP3 genotypes. No NP6 genotypes were detected in either epidemic. There was no association between NP genotype and disease severity (table 1). Group B RSV fall into NP genotypes 1,3 , and 6 , and these represent 10 of the isolates. There was no association between RSV group and disease severity.

The G gene PCR primers amplify group A RSV only, and 104 (91\%) of the RSV isolates fell into this group. On reverse transcription PCR, $82(79 \%)$ produced an amplicon of the correct size. For the remaining 22, no amplicon was detected despite repeated attempts on NPA and cultured virus. Each of the 82 amplicons fell into one of four distinct SHL lineages (G genotypes) on restriction endonuclease digestion (table 2). All the NP2 genotypes fell into three closely related lineages (SHL1, 3, 4), indistinguishable under the electrophoresis conditions used. The NP4 types fell into two lineages (SHL2 and SHL6). In the first epidemic, SHL2 and SHL6 were found in equal numbers, but in the second almost all were SHL2. On comparing the distribution of $G$ genotypes with the different gradings of disease severity (table 2), it was found that those infants infected with the SHL2 G genotype were more likely to suffer moderate or severe disease ( $p=0.04$, Fisher's exact test). Of the 40 infants infected with SHL2, 26 (65\%) had severe or moderate RSV disease, whereas only three $(30 \%)$ of those infected with SHL6 had moderate disease and none had severe disease.

\section{Discussion}

This is the first description of an association between RSV genotype and severity of infection. Although RSV infection varies across a spectrum from asymptomatic to life threatening, it is unclear why this should be. There is some evidence that severity of illness is related 
to the host's response to the virus. Recipients of a formalin killed RSV vaccine developed severe disease during subsequent natural RSV infection, ${ }^{918}$ suggesting a role for specific immunity in disease severity. Furthermore, in a murine model passive transfer of $\mathrm{CD}^{+}$and $\mathrm{CD}^{+} \mathrm{T}$ lymphocytes caused RSV infected animals to become ill and lose weight. ${ }^{19}$

Others have examined the possibility that disease severity might vary with the strain of RSV. RSV can be subdivided into two major antigenic subgroups (A and $\mathrm{B}$ ) on the basis of their reactions with monocloncal and polyclonal antisera. ${ }^{20}$ Although some reports have indicated that subgroup A RSV was associated with more severe disease ${ }^{21-24}$ others have found the converse. ${ }^{25}$ Some groups have detected no significant difference in severity between subgroup A and subgroup B RSV infection. ${ }^{26}{ }^{27}$ In the present study, we have examined the possibility that there might be variations in disease severity among RSV isolates of differing genotype.

Five of the six previously described $\mathrm{N}$ genotypes were found among our $114 \mathrm{RSV}$ isolates. As described previously in other settings, subgroup B RSV (which corresponds to $\mathrm{N}$ genotypes NP1, 3, and 6) was found in the minority of infections (10 out of 114 ; $9 \%) .{ }^{21-27}$ There was no significant association among either RSV N type or subgroups A and $\mathrm{B}$ and disease severity. The RSV G genotyping primers amplify only subgroup A RSV. It was surprising that 22 of the subgroup $A$ isolates $(21 \%)$ did not produce an amplicon despite the fact that virus was culturable and $\mathrm{N}$ genes detectable. Although the $\mathrm{G}$ gene primers are directed to conserved regions, it is possible that variations could have occurred in the primer binding sites thus preventing PCR amplification. Of the 82 isolates that produced amplicons, four distinct $G$ genotype lineages were detected (SHL1, 3, and 4 and SHL2, 5, and 6). These together with the $\mathrm{N}$ genotyping confirm previous reports that RSV epidemics are not homogenous, rather several different RSV strains cocirculate at the same time. ${ }^{28}{ }^{29}$ Similar RSV G types were circulating in Birmingham and Liverpool in the 1991 epidemic, ${ }^{28}$ but in 1992 SHL6 strains were found far more frequently in Birmingham, indicating that different RSV strains may circulate in different parts of the country during the same epidemic period.

In contrast with this lack of association between either RSV subgroup or N genotype and disease severity, there was a statistically significant association between infection with the SHL2 RSV G genotype and the occurrence of moderate to severe disease. As all the children studied were admitted to hospital, the distribution of severity was skewed towards children with severe disease in contrast with the spectrum normally found in the community. Therefore only a small proportion $(6 \%)$ of our patients had very mild disease. Nevertheless, that an association may exist is biologically plausible as the $G$ glycoprotein is expressed on the virus surface and the surface of virus infected cells and is thus important in immunogenicity. Furthermore the $G$ glycoprotein mediates the first step in RSV pathogenesis, namely attachment to the host cell. These early findings need further confirmation by large prospective studies encompassing a higher proportion of patients with very mild infection. Delineation of virus strains that are associated with severe disease will not only aid our understanding of RSV pathogenesis, but may help in designing appropriate subunit vaccines.

We thank the Foundation for the Study of Infant Deaths for financial support.

1 Berman S. Epidemiology of acute respiratory tract infections in children of developing countries. Rev Infect Dis 1991;13(suppl 6):S454-62.

2 Kim HW, Arrobio JO, Brandt CD, et al. Epidemiology of respiratory syncytial virus infection in Washington DC. I. Importance of virus in different respiratory tract disease syndromes and temporal distribution of infection. Am 7 Eyndromes and temporal

3 Stott EJ, Taylor G. Respiratory syncytial virus. Brief review. Arch Virol 1985;84:1-52.

4 Groothuis JR, Guiterrez KM, Lauer BA. Respiratory syncytial virus infection in children with bronchopulmonary dysplasia. Pediatrics 1988;82:199-203.

5 Parrott RH, Kim HW, Arrobio JO, et al. Epidemiology of respiratory syncytial virus infection in Washington DC. II. Infection and disease with respect of age, immunologic status, race and sex. Am F Epidemiol 1973;98:289-300.

6 McConnochie KM, Roghmann KJ. Wheezing at 8 and 13 years: changing importance of bronchiolitis and passive smoking. Pediatr Pulmonol 1989;6:138-46.

7 Laing I, Reidel F, Yap PL, Simpson H. Atopy predisposing to acute bronchiolitis during an epidemic of respiratory syncytial virus. BMF 1982;284:1070-2.

8 Groothuis JR, Simod EAF, Levin MJ, et al. Prophylaxis with respiratory syncytial virus immune globulin in high risk children. N Engl F Med 1993;329:1524-30.

9 Kim HW, Canchola JG, Brandt CD, et al. Respiratory syncytial virus disease in infants despite prior administration of antigenic inactivated vaccine. Am $\mathcal{f}$ Epidemiol 1969; 89:422-34.

10 Isaacs D. Prospects for a respiratory syncytial virus vaccine. Immunol Infect Dis 1991;1:355-9.

11 Collins PL, Huang YT, Wertz GW. Identification of a tenth mRNA of respiratory syncytial virus and assignment of polypeptides to the 10 viral genes. $\mathcal{F}$ Virol 1984;49:5728.

12 Cane PA, Pringle CR. Respiratory syncytial virus heterogeneity during an epidemic: analysis by limited nucleotide sequencing (SH gene) and restriction mapping (N gene). $\mathcal{F}$ Gequen Virol 1991;72:349-57.

13 Cane PA, Matthews DA, Pringle CR. Identification of variable domains of the attachment (G) protein of subgroup A respiratory syncytial viruses. F Gen Virol 1991; 72:2091-6.

14 Cane PA, Thomas HM, Simpson AF, Evans JE, Hart CA, Pringle CR. Analysis of the human immune serological Pringle CR. Analysis of the hum response to a variable region of the attachment $(G)$ protein of respiratory syncytial virus

15 Sullender WM, Mufson MA, Anderson LJ, Wertz GW. Genetic diversity of the attachment protein of subgroup B respiratory syncytial viruses. F Virol 1991;65:5425-34.

16 Smyth RL, Fletcher JN, Thomas HM, Hart CA. Immunoogical responses to respiratory syncytial virus infection in infancy. Arch Dis Child 1997;76:210-4.

17 Cane PA, Pringle CR. Molecular epidemiology of respiratory syncytial virus: rapid identification of subgroup A lintory syncytial virus: rapid identification
eages. F Virol Methods 1992;40:297-306.

18 Anderson LJ, Heilman CA. Protective and disease enhancing immune responses to respiratory syncytial virus. $\mathcal{F}$ Infect Dis 1995;171:1-7.

19 Alwan WH, Record FM, Openshaw PJM. CD4 ${ }^{+}$T cells clear virus but augment disease in mice infected with respiratory syncytial virus. Clin Exp Immunol 1992;88:52736 .

20 Anderson LJ, Hierholzer JC, Tsou C, et al. Antigenic haracterization of respiratory syncytial virus strains with monoclonal antibiotics. F Infect Dis 1985;151:626-33.

21 Taylor CE, Morrow S, Scott M, Young B, Toms GL. Comparative virulence of respiratory syncytial virus subgroups $\mathrm{A}$ and B. Lancet 1989;i:777-8.

22 Hall CB, Walsh EE, Schnabel KC, et al. Occurrence of groups A and B of respiratory syncytial virus over 15 years: 
associated epidemiologic and clinical characteristics in hospitalized and ambulatory children. F Infect Dis 1990; 162:1283-90.

23 McConnochie KM, Hall CB, Walsh EE, Roughmann KJ. Variation in severity of respiratory syncytial virus infections with sybtype. F Pediatr 1990;117:52-62.

24 Walsh EE, McConnochie KM, Long CE, Hall CB. Severity of respiratory syncytial virus infections is related to virus strain. F Infect Dis 1997;175:814-20.

25 Straliotto SM, Roitman B, Lima JB, Fischer GB, Siquera MM. Respiratory syncytial virus bronchiolitis: comparative study of RSV groups A and B infected children. Rev Soc Bras Med Trop 1994;27:1-4.
26 McIntosh DG, De Silva LM, Oates RK. Clinical severity frespiratory syncytial virus group A and B infection in Sydney, Australia. Pediatr Infect Dis f 1993;12:815-9.

27 Kneyber MCJ, Brandenburg $\mathrm{AH}$, Rothbarth $\mathrm{Ph} \mathrm{H}$, de Groot R, Ott A, van Steensel-Moll HA. Relationship between clinical severity of respiratory syncytial virus infection and subtype. Arch Dis Child 1996;75:13740.

28 Cane PA, Matthews DA, Pringle CR. Analysis of respiratory syncytial virus strain variation in successive epidemics in one city. F Clin Microbiol 1994;32:1-4.

29 Mlinaric-Galinovic G, Chonmaitree T, Cane PA, Pringle CR, Ogra PL. Antigenic diversity of respiratory syncytial virus subgroup B strains circulating during a community outbreak of infection. $\mathcal{F}$ Med Virol 1994;42:380-4. 